\title{
Orbital pseudotumor: a differential diagnosis of Graves' ophthalmopathy
}

\author{
Pseudotumor de órbita: um diagnóstico \\ diferencial de oftalmopatia de Graves
}

Luciana Souza Cruz Caminha', Elisa Rebelo Pinto', Priscila Alves Medeiros de

Sousa', Ricardo Andrade Oliveira', Flavia Lucia Conceiçao', Mario Vaisman'

\section{SUMMARY}

The objective of this study is to report and discuss a rare and inflammatory cause of exophthalmos. This report describes a patient with exophthalmos, who was initially diagnosed with euthyroid Graves' with good response to therapy. After 8 years of follow-up, she had recurrence of symptoms and a new evaluation revealed the final diagnosis of orbital pseudotumor. Orbital pseudotumor is an uncommon disorder that both radiologically and clinically mimics a malignant process or other inflammatory disease, such as Graves' ophthalmopathy. Arq Bras Endocrinol Metab. 2011;55(1):85-8

\section{SUMÁRIO}

O objetivo deste estudo é relatar e discutir uma causa de exoftalmia rara e inflamatória. Este artigo relata uma paciente com exoftalmia que recebeu diagnóstico inicial de oftalmopatia de Graves eutireoideana com boa resposta à terapia. Após oito anos de seguimento, houve recorrência dos sintomas e uma nova avaliação revelou o diagnóstico final de pseudotumor orbitário. Pseudotumor orbitário é uma condição incomum que mimetiza clínica e radiologicamente uma doença maligna ou inflamatória, como a oftalmopatia de Graves. Arq Bras Endocrinol Metab. 2011;55(1):85-8

1 Endocrinology Service, Hospital Universitário Clementino Fraga Filho (HUCFF), Universidade Federal do Rio de Janeiro (UFRJ), RJ, Brazil

\section{INTRODUCTION}

$\mathrm{T}$ the most common cause of proptosis, unilateral or bilateral, is Graves' ophthalmopathy. It is usually bilateral and associated with hyperthyroidism, but it can also be asymmetric or unilateral. The ophtalmopathy may precede (euthyroid Graves' disease), follow or occur simultaneously with hyperthyroidism $(1,2)$. Diagnosis is straightforward in patients with hyperthyroidism and bilateral disease, but it should also be considered in patients with no thyroid dysfunction or unilateral disease (3).

Since several conditions can cause exophthalmos when diagnosis is uncertain orbital imaging (computed tomography - CT or magnetic resonance - MRI) should be done. Measurement of thyrotropin-receptor antibodies (TRAb) should be performed due to their high specificity and sensitivity in Graves' disease. These conditions include orbital pseudotumor, Cushing's syndrome, obesity, idiopathic miositis and cellulitis, gra- nulomatous disorders, primary or metastatic tumors, fistulas in the cavernous portion of the carotid artery and other vascular conditions (3).

This report describes a patient with exophthalmos, who was initially diagnosed with euthyroid Graves' ophthalmopathy but had the final diagnosis of orbital pseudotumor, after 8 years of follow-up.

\section{CASE REPORT}

In 2000, a 39-year-old woman came to the hospital for evaluation of unilateral proptosis in the right eye, which had developed 2 years before. At this time, she complained of tearing and grittiness with no decrease in visual acuity. There was no sign/symptom of thyroid dysfunction; she had been taking propylthiouracil for 3 months despite normal hormone levels. She had a history of peripartum cardiomyopathy in 1998. Clinical examination showed proptosis in the right eye, associated with 
mild swelling, redness, and normal eye movements; no pain, diplopia or goiter. Lab tests showed normal thyroid function tests, negative antithyroglobulin and antithyroid peroxidase antibodies. Orbital CT and ultrasound revealed enlargement of lateral rectus muscle and higher density of orbital fat, suggesting Graves' ophtalmopathy. Intravenous corticosteroid followed by oral prednisone was administered with good clinical response.

During 7 years of follow-up she did not show any signs or symptoms of recurrence (2001-2008). In March, 2008 she presented mild proptosis, redness, and swelling of the left eye. She continued to show no decrease in visual acuity or limitation of eye movements. A new orbital CT revealed a retrobulbar mass which involved the optic nerve (without affecting it), exhibiting enhancement post contrast media injection. Muscle and orbital fat were normal (Figure 1). MRI showed isointense images on T1 and T2 (Figure 2). Lab tests showed euthyroidism. TRAb and anti-TPO were negative. Retrobulbar biopsy was performed and revealed chronic inflammatory infiltrate. A sample of striated muscle taken was normal, excluding Graves' ophthalmopathy. During clinical investigation the proptosis, periorbital swelling, and ecchymosis worsened (Figure 3 ).

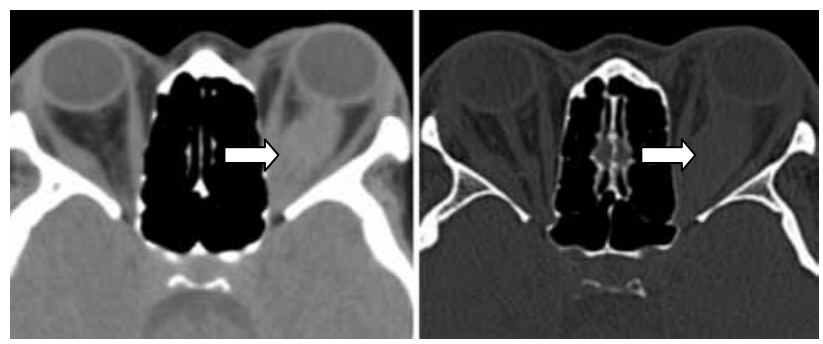

Figure 1. Computed tomography images. Note the mass in the left orbit.
Considering the clinical history and histopathological examination, diagnosis of orbital pseudotumor was made and intravenous glucocorticoid followed by oral prednisone was prescribed. Administration of intravenous methylprednisolone resulted in marked improvement within 24 hours (Figure 4).

Considering the clinical history and histopathological examination, the diagnosis of orbital pseudotumor was made and intravenous glucocorticoid followed by oral prednisone was prescribed. Administration of intravenous methylprednisolone resulted in marked improvement within 24 hours (Figure 4).

\section{DISCUSSION}

Orbital pseudotumor (OP) or idiopathic orbital inflammatory disease was first described in 1903 by Gleason and by Busse and Hochheim (4). Inflammatory pseudotumor most often occurs in the lung, liver, and orbit but it has been reported to occur in nearly every organ in the body $(5,6)$.

It is an uncommon disease and is defined as a benign, non-infectious, space-occupying orbital lesion without identifiable local or systemic cause. The inflammatory process may involve any orbit tissue and it has variable clinical features (myositis, dacryoadenitis, perineuritis, tendonitis, episcleritis, and localized mass) (5).

The pathogenesis is not clear. It has been associated with infection, trauma, and surgery. Several lines of evidence suggest an immune-mediated process. An association with systemic immunologic disorders including Crohn's disease, Sjogren's syndrome, Becet's disease, lupus, rheumatoid arthritis, diabetes mellitus, myasthenia gravis, and ankylosing spondylitis have been reported $(5,6)$. Moreover, OP favorably responds to glucocorticoid therapy and other immunosuppressive agents.

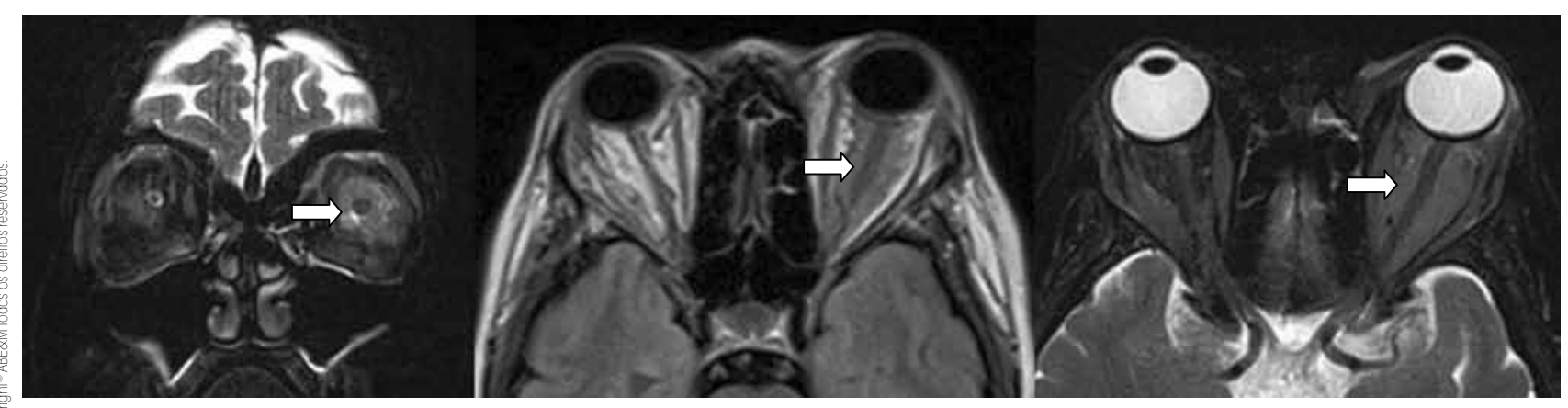

Figure 2. 0n T1 and T2-weighted magnetic resonance images. Note the mass in the left. 


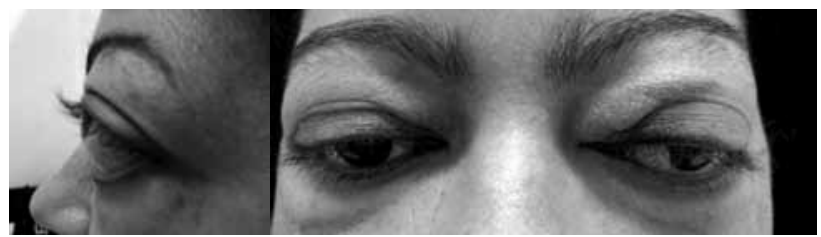

Figure 3. Before treatment. Proptosis and important inflammatory signs on the left.

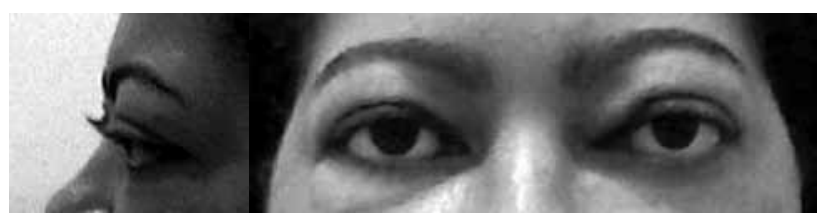

Figura 4. After treatment: important improvement of proptosis and inflammatory signs.

Orbital pseudotumor occurs more often in the third to sixth decades (5) with no strong sex predilection (4); it accounts for $4.7 \%$ to $6.3 \%$ of orbital disorders and is the third most common orbital disease (following Graves' orbitopathy and lymphoproliferative disease) $(4,7)$. Unilateral disease is the rule but bilateral presentations are not uncommon, especially in children. Symptoms most commonly develop acutely (hours or days) but may be subacute or chronic and present with proptosis and inflammatory signs (pain, swelling and erythema); ptosis, chemosis, motility dysfunction, and optic neurophaty may also occur (5).

Clinical diagnosis of orbital pseudotumor is made by exclusion of other conditions. A biopsy must be considered when the diagnosis is uncertain after clinical examination and images; when the disease involves the anterior orbital (easy approach); in recurrent episodes or when the patient is refractory to treatment $(5,8)$. The main differential diagnoses that should be excluded are: infections, inflammatory reaction to trauma or foreign body, thyroid dysfunction, vasculitis (Wegner's granulomatosis, polyarteritis nodosa and giant cell arteritis), sarcoidosis, neoplasia (primary and metastatic tumors of breast, lung, prostate or kidney), lymphoma, arteriovenous fistula and malformations (4).

Orbital imaging is an essential tool because it allows for the characterization and localization of disorder without surgical intervention. On CT scan, a moderately enhanced focal or diffuse mass frequently accompanied by infiltration of retrobulbar fat is usually seen. On MRI images, OP is usually isointense to hypointense in relation to muscle on $\mathrm{Tl}$-weighted images, with a rela- tive isointense T2 signal. It can also show proptosis, optic nerve thickening, uveal-scleral thickening, lachrymal gland infiltration and extraocular muscle enlargement (with muscle tendon or sheath enlargement). This radiologic feature is useful to differentiate OP from Graves' ophtalmophaty, since the latter is commonly bilateral and mainly involves orbital fat and extraocular muscle with tendon sparing (spindle-shapped) (2-4).

Histopathological analysis reveals pleomorphic inflammatory cell infiltration followed by reactive fibrosis. The sclerotic form is considered to have poor prognosis (4).

Primary treatment consists of systemic steroid therapy. Observation can be considered for mild disease because spontaneous remission has been reported after a few weeks. Some authors suggest that the use of oral non-steroidal anti-inflammatory (ibuprofen, for example) should precede steroid therapy since it is often effective $(4,5,8)$. For moderate to severe clinical presentation, oral prednisone can be started with an initial dosage of $60 \mathrm{mg}$ to $100 \mathrm{mg}$ per day for 1 to 2 weeks followed by progressive reduction, depending on clinical response $(4,5)$. Intravenous corticosteroid should be initiated if optic nerve dysfunction occurs (2). In general, the treatment results in dramatic improvement within 48-72 hours, mainly of inflammatory signs and pain (6). Although many patients do have a favorable response to corticosteroids, incomplete resolution and recurrence are common. Recurrence rates as high $25 \%$ $52 \%$ have been reported $(4,5)$.

Orbital irradiation may be useful as an additional therapy and may be considered when there is no clinical improvement after 2 weeks of adequate therapy or if the patient becomes steroid-dependent, or had a serious adverse reaction to the steroid. Even a low dose treatment (10-20 Gy fractioned over 10 days) may produce long term remission. Because recurrence/resistance is common other immunosuppressive agents have been used with variable results. Cyclophosphamide, chlorambucil, mycophenolate mofetil, methotrexate have been used in refractory cases $(4,5)$.

Surgical debulking is indicated for patients with severely progressive and disabling clinical course (e.g., orbital apex syndrome with optic nerve compression) or when the lesion is focal and easily approachable (4).

In conclusion, orbital pseudotumor is an uncommon disorder that radiologically and clinically mimics a malignant process or other inflammatory diseases. In this reported case, there was probably a recurrence after 7 years of remission. She had a favorable response to steroid 
therapy, as in the first episode. The patient has a history of peripartum cardiomyopathy, a disorder of uncertain etiology, but autoimmunity has been implicated, as in OP.

Disclosure: no potential conflict of interest relevant to this article was reported.

\section{REFERENCES}

1. Vilar L. Endocrinologia clínica. 3rd ed. Rio de Janeiro: Guanabara Koogan; 2006.

2. Winn R. Youmans. Neurological surgery. 5th ed. Philadelphia: Saunders; 2004.
3. Bartalena L. Tanda AM. Graves' Ophthalmopathy. N Engl J Med. 2006;360:994-1001.

4. Yuen SJ, Rubin PA. Idiopathic orbital inflammation: distribution, clinical features, and treatment outcome. Arch Ophthalmol. 2003;121:491-9.

5. Kanski JJ. Clinical ophthalmology: a systematic approach. 6th ed. Philadelphia: Elsevier; 2008.

6. McCall T, Fassett DR, Lyons G, Couldwell WT. Inflammatory pseudotumor of the cavernous sinus and skull base. Neurosurg Rev. 2006;29:194-200.

7. Narla L, Newman B, Spottswood SS, Narla S, Kolli R. Inflammatory pseudotumor. Radiographics. 2003;23:719-29.

8. NunesTP, Roizemblatt R, Miki G, Garcia R, Santo RM, Olivalves E, et al. Idiopathic orbital inflammation with extraorbital extension: case report. Arq Bras Oftalmol. 2007;70(3):540-3. 